\title{
Descontinuidades produtivas e tecnológicas na estrutura industrial da economia brasileira
}

\author{
Rosembergue Valverde \\ Professor - Departamento de Ciências Sociais Aplicadas - Universidade Estadual de Feira de Santana (UEFS) \\ Endereço: Av. Transnordestina, s/n - Novo Horizonte - Feira de Santana - Bahia \\ CEP: 44036-900 - E-mail: rosemberguevalvred@uefs.br
}

Recebido: 09/09/2016. Aceite: 26/06/2017.

\section{Resumo}

O objetivo deste artigo é avaliar a capacidade da economia brasileira de sustentar taxas de crescimento em longo prazo, considerando as complementaridades técnicas intersetoriais como vetor de absorção e difusão tecnológicas na estrutura industrial. Para realizar essa tarefa, recorre-se às teorias neo-schumpeteriana, que descrevem os processos de absorção e difusão tecnológicas e à construção de um modelo de crescimento multissetorial de inspiração neorricardiana do tipo Sraffa-Von Neumann. Em acordo com os procedimentos metodológicos adotados, identificam-se descontinuidades produtivas, características de estrangulamentos da produção, que comprometem as condições de crescimento de longo prazo e os processos de absorção e difusão tecnológicas da economia brasileira. Em conclusão, destaca-se a existência de pontos de estrangulamentos de produção em setores com elevado grau de basicidade, fundamentais para a reprodução da estrutura produtiva da economia brasileira.

\section{Palavras-Chave}

Estrutura industrial. Crescimento econômico. Inovações tecnológicas.

\begin{abstract}
The aim of this article is to evaluate the Brazilian economy's capacity to sustain long-term growth rates based on intersectoral technological complementarity as a vector of technology absorption and diffusion through its industrial structure. To this end, it refers to neo-Schumpeterian theories that describe the process of technology absorption and diffusion and the construction of a multisector growth model inspired by Sraffa and Von Neumann's Neo-Ricardian theories. The methodological procedures enabled us to identify production discontinuities and bottlenecks which could jeopardize the Brazilian economy's long-term growth and its technology absorption and diffusion processes. In conclusion, we highlight the existence of production bottlenecks in key economic sectors, fundamental to the reproduction of the Brazilian economy's production structure.
\end{abstract}

\section{Keywords}

Industrial Structure. Economic growth. Technological innovations.

\section{JEL Classification}

L11. L16. L23. 


\section{Introdução}

O objetivo deste artigo é avaliar a capacidade da economia brasileira de sustentar taxas de crescimento em longo prazo, considerando as complementaridades técnicas intersetoriais como vetor de absorção e difusão tecnológicas na estrutura industrial. Para realizar essa tarefa, recorre-se às teorias neo-schumpeterianas que descrevem os processos de absorção e difusão tecnológicas e à construção de um modelo de crescimento multissetorial de inspiração neorricardiana do tipo Sraffa-Von Neumann. Em acordo com os procedimentos metodológicos adotados, identificam-se descontinuidades produtivas, características de estrangulamentos da produção, que comprometem as condições de crescimento de longo prazo e os processos de absorção e difusão tecnológicas da economia brasileira.

O artigo está organizado em quatro seções, incluindo esta introdução. $\mathrm{Na}$ segunda seção, efetua-se uma breve revisão das teorias neo-schumpeterianas sobre os processos de absorção e inovações tecnológicas na estrutura produtiva de uma economia qualquer. Enumeram-se os principais fatores determinantes, ao tempo em que se descrevem as relações entre inovações tecnológicas e crescimento econômico como um processo único mediante uma dinâmica circular e cumulativa. À luz desse escopo teórico, ressalte-se que os caminhos, a velocidade e a amplitude das difusões tecnológicas variam em acordo com as especificidades das estruturas industriais de cada economia. Na terceira seção, constrói-se uma trajetória de crescimento equilibrado com base em um modelo de crescimento multissetorial de inspiração neorricardiana. Nos modelos do tipo Sraffa-Von Neumann, a trajetória de crescimento de longo prazo, na taxa máxima de expansão, exige estrita complementaridade da produção setorial. Se essa complementaridade não é satisfeita, a economia não é capaz de crescer a taxa máxima de expansão, e os processos de absorção e difusão tecnológicas não são capazes de se espalhar sobre toda a estrutura produtiva. Nesses tipos de modelos, depreendem-se duas trajetórias de crescimento. A primeira, denominada "trajetória dourada", é aquela em que todo o excedente da produção de um período serve como meio de produção do período subsequente. Essa trajetória serve para hierarquizar a estrutura produtiva em termos do grau de basicidade e qualificar possíveis pontos de estrangulamentos da produção. A segunda, denominada "trajetória prateada", é aquela compatível com uma estrutura de repartição de renda inscrita em um vetor de demanda 
final. ${ }^{1}$ Quando comparada com a trajetória de crescimento efetivamente observada na economia, ela serve para identificar possíveis pontos de estrangulamentos da produção. Na quarta seção, recorrendo-se à base conceitual descrita nas seções anteriores, desenvolve-se o exercício de aplicação para a economia brasileira. Fundamentado nos ensinamentos adquiridos, procede-se ao estudo dos problemas das descontinuidades da produção setorial presentes na estrutura industrial da economia brasileira, representada por uma Matriz de Relações Intersetoriais. Para tal, comparam-se as proporções da produção setorial observadas no ano de referência com as proporções da produção setorial de uma trajetória de crescimento balanceado, capaz de sustentar taxas de crescimento de longo prazo e garantir os processos de absorção e difusão tecnológicas. Em linhas gerais, atesta-se a presença de fortes descontinuidades produtivas e tecnológicas, características de pontos de estrangulamento de produção. Mais grave ainda é que os estrangulamentos técnico-produtivos encontrados localizam-se em setores fundamentais para a reprodução da estrutura da economia brasileira.

Em conclusão, com base nos resultados obtidos, arrisca-se tecer alguns princípios que deveriam nortear uma política industrial para a economia brasileira capaz de assegurar as condições de crescimento de longo prazo e a aceleração dos processos de absorção e difusão tecnológicas. Por fim, enunciam-se alguns limites da pesquisa e a possibilidade de desenvolvimentos futuros.

\section{Complementaridades técnicas e difusão tecnológica}

Teorias desenvolvimentistas de inspiração neo-schumpeterianas permitem que as relações entre inovações tecnológicas e crescimento econômico possam ser descritas como um processo único numa dinâmica circular e cumulativa. Nesse processo, sustentações de taxas de crescimento no longo prazo e reversões de armadilhas de pobreza e de renda média dependem

1 As expressões "trajetória dourada" e "trajetória prateada" aludem à terminologia utilizada por Joan Robinson (1956) "golden age" e "platinum age", que contrastam com desequilíbrios inevitáveis e instabilidade inerente ao sistema de produção capitalista. Por isso, essas trajetórias, quando confrontadas com aquelas efetivamente observadas na economia, servem apenas para identificar desequilíbrios, descontinuidades produtivas e pontos de estrangulamentos de produção. 
fortemente do ambiente macroeconômico e institucional de cada economia. Sobre os aspectos macroeconômicos, observam-se, como base para sustentação do crescimento em longo prazo, fatores como estrutura da repartição da renda, qualidade da especialização internacional, inserção em cadeias produtivas globais, capacidade de atração de investimentos diretos e coerência da estrutura produtiva. No que concerne aos aspectos institucionais, um sistema nacional de inovações, uma política industrial ativa e um ambiente de negócios que promova inovações são exemplos de fatores que podem guiar positivamente as transformações técnico-produtivas e garantir a sustentabilidade do crescimento no longo prazo. ${ }^{2}$

Os processos de criação, absorção e difusão tecnológicas são incrementais, cumulativos e sujeitos a uma dinâmica de aprendizagem longa e complexa e, por isso, são, igualmente, influenciados por uma série de fatores microeconômicos. Assim, os custos de adoção das inovações tecnológicas, o volume e a eficiência dos gastos com pesquisa e desenvolvimento, o estoque inicial de conhecimento de cada economia, a disponibilidade de capital humano, a infraestrutura de transportes e de telecomunicações são também decisivos. Somando tudo, as interações entre inovações tecnológicas e crescimento econômico dependem, em pé de igualdade, de fatores macroeconômicos, institucionais e de natureza microeconômica. $\mathrm{Se}$, intuitivamente, esses fatores sempre estiveram presentes nos quadros analíticos dos economistas até o início dos anos de 1980, crescimento econômico e inovações tecnológicas eram tratados separadamente pela teoria dominante. Basta lembrar que, no modelo de crescimento de Solow (1956, 1957), Cass (1963) e Koopmanns (1963), a tecnologia é uma variável exógena.

Em busca de integração entre crescimento econômico e inovações tecnológicas, um caminho foi aberto pelas teorias do crescimento endógeno. A primeira família desses modelos foi construída a partir dos trabalhos de Romer (1986), Lucas (1988), Barro (1990) e Rebelo (1991). Com hipóteses

2 Em acordo com Ricardo Bielschowsky (2013), as estratégias de crescimento em longo prazo com base no desenvolvimento industrial devem focar nos encadeamentos produtivos. Como atestam Nelson Marconi, Igor Rocha e Guilherme Magacho (2016), analisando as relações entre estrutura de produção e crescimento econômico, através de um modelo de insumo-produto, para a economia brasileira, a capacidade de sustentação do crescimento econômico a partir das exportações de commodities é baixa. Ou ainda como demostra Vinícius Pereira (2016), "entre 1995 e 2011 houve um esgarçamento do tecido produtivo brasileiro ocasionando a redução da capacidade de indução ao crescimento". Acrescenta-se que não se deve perder de vista que esses encadeamentos da produção intersetorial, tanto em setores nobres, quanto em setores tradicionais, tanto em commodities, quanto em setores relacionados à manufatura, podem esbarrar em estrangulamentos da produção. 
de rendimentos crescentes, economias de escala e concorrência imperfeita, esses trabalhos ressaltam o papel das externalidades como um fator de retroalimentação do crescimento econômico. Somadas às externalidades, a segunda família de modelos de crescimento endógeno destaca o papel dos investimentos em $\mathrm{P} \& \mathrm{D}$ como fonte do progresso técnico e crescimento econômico. Os trabalhos fundadores dessa linhagem são atribuídos a Romer (1990), Grosman e Helpman (1991) e Aghion e Howitt (1992). Os trabalhos desses dois últimos autores enquadram-se numa perspectiva neo-schumpeteriana, segundo a qual o crescimento econômico resulta de uma busca incessante de melhorias da qualidade de produtos e processos, o que torna os seus sucedâneos obsoletos. ${ }^{3}$

Ainda na busca de integração entre as teorias do crescimento econômico e inovações tecnológicas, outro caminho foi aberto pelos teóricos evolucionistas e neo-schumpeterianos. Com base no trabalho seminal de Nelson e Winter (1982), as trajetórias de crescimento e inovação passaram a ser influenciadas por elementos de hereditariedade, mutações e seleção. Desse modo, rendimentos crescentes a escala, associados a mecanismos de aprendizagem pela prática, por uso e por interações, podem explicar a não convergência absoluta ou condicional para um estado estacionário. Já os neo-schumpeterianos da Universidade de Sussex, sob a liderança de Christopher Freeman, estudam as relações entre inovações e crescimento econômico como um processo interativo. Na dinâmica desse processo, as inovações tecnológicas difundem-se pelo conjunto da economia afetando as condições dos desequilíbrios macroeconômicos. Mudanças nos paradigmas técnico-econômicos, na perspectiva de Perez (2009), afetam as trajetórias tecnológicas e de crescimento econômico na conceituação de Dosi (1982).

Permanecendo na perspectiva neo-schumpeteriana, à luz do conceito de Sistema Nacional de Inovações, forjado por Freeman (2008) e Lundvall (1988, 1992), tem-se que as transformações tecnológicas e as dinâmicas de difusão e absorção do progresso técnico divergem significativamente de uma economia para outra, mesmo quando se trata de economias com níveis de desenvolvimento comparáveis. Em outras palavras, as "aptidões" das economias nacionais para criar, absorver e difundir inovações tecnológicas e para promover trajetórias de crescimento sustentáveis em longo prazo dependem de fatores institucionais no mesmo nível daqueles de caráter es-

3 Os leitores interessados podem consultar um recente recenseamento elaborado por Philippe Aghion, Ufuk Akcigit e Peter Howitt (2013) sobre o legado neo-schumpeteriano para a teoria do crescimento econômico. 
tritamente econômico. O "espírito animal" dos capitalistas é condicionado pelo ambiente macroeconômico e institucional. Mais recentemente, os neo-schumpeterianos de Sussex ampliaram os conceitos e as análises sob a liderança de Mariana Mazzucato. Da ampla agenda dessa pesquisadora, destacam-se os estudos sobre o papel do Estado (Mazzucato 2014) e sobre a função das finanças na promoção de inovações tecnológicas e de crescimento econômico (Mazzucato 2013).

Ressalta-se aqui um ponto comum a todas as releituras da teoria schumpeteriana sobre as relações entre inovações e crescimento econômico, a saber: os caminhos, a velocidade e a amplitude das difusões tecnológicas variam em acordo com as especificidades das estruturas industriais das economias nacionais. Em geral, a coerência da estrutura produtiva condiciona os modos de propagação do progresso técnico. Entretanto, na linha dos neo-schumpeterianos de Sussex, Pavitt (1984) argumenta que as inovações tecnológicas se concentram em certo número de setores a partir dos quais são difundidos para a economia como um todo. Segundo a taxonomia criada por Pavitt (1984), existiriam setores mais difusores de tecnologias que outros, independente das particularidades de cada economia. ${ }^{4}$ Visando corrigir imperfeições existentes nessa taxonomia, a lista de setores com maior poder de difusão das inovações tecnológicas foi atualizada por Archibugi (2001) e, posteriormente, por Castellacci (2009).

Neste trabalho, adota-se uma perspectiva um pouco distinta. Ao invés de buscar setores padrões a partir dos quais difundem-se as inovações tecnológicas, supõe-se que cada economia possui um conjunto de características que contribui para acelerar ou frear os processos de difusão de inovações tecnológicas. Setores tradicionais podem apresentar cadeias produtivas longas o suficiente para promover inovações induzidas e sustentar taxas de crescimento econômico em longo prazo. Por exemplo, setores do agronegócio unem-se à ponta das inovações em ciência e tecnologia por meio das biotecnologias. Da mesma forma, setores ligados à mineração podem apresentar cadeias produtivas suficientemente longas para aprimorar as relações entre fornecedores, produtores e consumidores. Argumenta-se

4 Podem-se encontrar estudos sobre padrões setoriais de inovação aplicados para a indústria brasileira, a exemplo de Bruno Campos e Ana Ruiz (2009); Daniela de Castro (2010); Conceição Silva e Wilson Suzigan (2014); Paula Hamberger e Marisa Botelho (2015). Em geral, esses trabalhos validam a taxonomia de Pavitt (1984). Entretanto, como se esperava, neste trabalho, existem setores fora da taxonomia que aparecem como inovadores e setores inovadores que não constam da taxonomia pavittiana. Cada economia possui uma estrutura particular que transforma certos setores em mais ou menos absorvedores ou difusores de inovações tecnológicas. 
que, independente dos setores, quanto maiores as complementaridades técnico-industriais, mais fluidos são os processos de absorção e difusão tecnológicas. Ao contrário, quanto maior a heterogeneidade técnico-produtiva da estrutura industrial, maior a dificuldade de absorção e difusão de inovações tecnológicas e a capacidade de sustentar taxas de crescimento econômico. ${ }^{5}$

A heterogeneidade técnico-produtiva restringe as inovações tecnológicas a certos segmentos produtivos, estrangulando as inovações induzidas. Em termos dinâmicos, isso contribui para formação de um círculo vicioso em que fenômenos de irreversibilidade e histereses contribuem para aumentar as disparidades existentes entre os níveis de desenvolvimento tecnológico dos setores produtivos. Argumenta-se que as transferências tecnológicas de uma atividade a outra dependem de forma estrutural da qualidade das interações (mercantis e tácitas) entre produtores e fornecedores e entre produtores e consumidores. Entretanto, mais uma vez, mantendo a distância da taxonomia de Pavitt (1984) e suas atualizações, vale lembrar que cada economia apresenta a própria hierarquia dos setores industriais quanto a geração, absorção e difusão das inovações na estrutura industrial. Como grande parte das interações entre produtores e fornecedores provém da interdependência da produção entre os setores produtivos, pode-se inferir que as relações intersetoriais (técnico-econômicas e organizacionais) representam um importante vetor de transmissão das inovações tecnológicas. Como demostram Malerba (2002) e Geels (2004), as inovações transformam os setores produtivos e modificam as relações intersetoriais que, por sua vez, condicionam as características dos ciclos econômicos.

5 A questão das influências da heterogeneidade da estrutura industrial sobre as condições de crescimento de longo prazo e os processos de absorção e difusão tecnológicas nos remetem ao conceito de heterogeneidade estrutural forjado por Anibal Pinto (1969). Em acordo com estudo da CEPAL (2010), a manifestação da heterogeneidade estrutural pode ser aprendida por meio de duas características que marcam a estrutura produtiva das economias subdesenvolvidas. A primeira concerne às defasagens tecnológicas das economias periféricas com relação à fronteira tecnológica das economias desenvolvidas. A segunda diz respeito às diferenças de produtividade intra e intersetoriais existentes na estrutura produtiva dessas economias. Essas características se retroalimentam por meio de um círculo vicioso difícil de ser quebrado. Para uma excelente discussão sobre heterogeneidade na produtividade das firmas brasileiras, recomenda-se a leitura do trabalho de Eva Catela e Gabriel Porcile (2013). Para uma avaliação da heterogeneidade estrutural da economia brasileira com base nas diferenças de produtividade, pode-se consultar o trabalho de Carolina Cândido (2014). Aqui ressalta-se outro aspecto da heterogeneidade estrutural, concentrando a análise nos hiatos existentes entre as complementaridades técnico-produtivas intersetoriais. Argumenta-se que as diferenças de produtividade intra e intersetoriais se traduzem também em falta de complementaridade da produção intersetorial que, por sua vez, restringe a capacidade de absorção e difusão tecnológicas e a sustentação de taxas de crescimento em longo prazo. 
Nessa mesma linha, Malerba e Nelson (2011) demostram que o sistema setorial de inovações e produção condiciona as trajetórias de crescimento econômico.

Adota-se a ideia de que as complementaridades da produção setorial podem servir como critério para avaliação da coerência da estrutura produtiva e, portanto, como condição necessária para uma eficaz absorção e difusão das inovações tecnológicas. Em termos dinâmicos, a existência de complementaridades entre as produções intersetoriais significa que o crescimento econômico pode ser sustentado em longo prazo sem ser interrompido por pontos de estrangulamento da produção. É evidente que a existência de complementaridades técnicas é uma condição necessária, mas não suficiente, para reproduzir toda a coerência tecnológica. Por exemplo, sabe-se que as instituições desempenham um papel fundamental na transmissão das inovações, sobretudo dos setores de maior intensidade tecnológica para os setores tradicionais em cada economia. Nesse caso, a prudência sugere que as análises sejam complementadas por estudos dos sistemas nacionais de inovações, o que, neste momento, foge ao escopo da pesquisa. Entretanto, as sinergias tecnológicas exigem sempre a presença de complementaridades técnicas. Dessa forma, o estudo das complementaridades da produção setorial revela um importante aspecto da coerência reprodutiva de uma economia qualquer, oferecendo uma primeira ideia da capacidade de absorção e difusão de inovações tecnológicas.

A ideia de complementaridade da produção intersetorial como um elemento de absorção e de difusão das inovações tecnológicas nos traz de volta aos economistas clássicos por meio do conceito de reprodução econômica. Nesse quadro analítico, as inter-relações dos setores produtivos são o meio de transmissão de inovações tecnológicas que se propagam para atingir toda a estrutura industrial. É pelas relações de interdependência técnica que se realiza o processo cumulativo de aprendizagem tecnológica. Assim, a coerência das relações técnicas intra e intersetoriais é a garantia do crescimento em longo prazo, constituindo-se, então, no suporte econômico para absorção e difusão das inovações tecnológicas.

Para cada estrutura industrial, existe um conjunto de setores particulares, que ocupa posição estratégica no processo de difusão tecnológica. Utilizando a nomenclatura de Sraffa (1960), esses corresponderiam aos setores básicos da economia. Se a coerência técnico-produtiva entre os setores é satisfeita, os fluxos de inovações tecnológicas podem se difundir 
a partir dos setores básicos para a demanda final, a jusante da própria produção e, ainda, a montante, em direção às indústrias de bens de equipamentos. Assim, os modos de difusão das inovações tecnológicas dependem simultaneamente das características das estruturas industriais de cada economia nacional e da qualidade das relações mercantis e tácitas entre produtores e fornecedores e, de maneira mais geral, entre produtores e consumidores. São esses dois aspectos que definem os caminhos dos processos de criação, absorção, aprendizagem e difusão tecnológicas.

Os processos de difusão intersetorial das tecnologias por meio do sistema setorial de inovações e produção, ainda no sentido utilizado por Malerba e Nelson (2011), serão mais ou menos eficientes em função das sinergias entre os setores produtivos. É certo que essas sinergias dependem da proximidade tecnológica e organizacional entre os setores sem necessariamente passar pelas relações mercantis estabelecidas entre eles. Entretanto, se essas condições não são satisfeitas, pode ocorrer a formação de pontos de estrangulamento da produção, que constituem barreiras à absorção e à difusão das inovações tecnológicas. Uma possibilidade de rejeição da hipótese de convergência entre taxas de crescimento das economias nacionais implícita aos modelos de crescimento tradicionais pode ser buscada na maior ou menor coerência da estrutura produtiva das economias nacionais. Essa condição pode facilitar ou dificultar a absorção e difusão de inovações e a sustentação de taxas de crescimento de longo prazo.

Para o caso de economias em desenvolvimento, sobretudo aquelas que possam se encontrar presas em armadilhas de renda média, espera-se que as heterogeneidades das estruturas industriais apareçam como um traço predominante. Espera-se igualmente que existam desproporções e descontinuidades da produção setorial que reflitam contradições entre as normas de valorização do capital e as condições necessárias à reprodução econômica. Estando as normas de valorização do capital ligadas às ações dos capitais individuais e às decisões de investir dos capitalistas, a materialização se concretiza nas quantidades efetivamente produzidas e realizadas em cada um dos setores produtivos, o que corresponde, então, à trajetória de crescimento objetivamente observada na economia durante um período qualquer. Quanto às condições necessárias à reprodução econômica, essas podem ser representadas pelas complementaridades da produção setorial, garantindo uma taxa de crescimento sustentada em longo prazo, sem que se verifique a existência de pontos de estrangulamentos da produção. 
Vale ressaltar que, em princípio, nada garante que o comportamento dos capitalistas seja tal que as decisões individuais de investir conduzam a proporções compatíveis com as condições necessárias à reprodução econômica. Quando se agregam ainda os diferentes tempos de rotação do capital em cada setor produtivo, essas condições são ainda mais difíceis de serem realizadas. Como ensina Kalecki (1977), os capitalistas não tomam decisões de investir como classe; elas são tomadas a fim de assegurar a racionalidade microeconômica, no âmbito da reprodução do capital individual, e não pela racionalidade macroeconômica no âmbito do capital social. Assim, as decisões capitalistas resultam de expectativas submetidas a constantes revisões ao longo do ciclo de produção em função das transformações do estado de coisas. Cada segmento de produção responde diferentemente a essas transformações. As possibilidades do aparecimento de descontinuidades técnico-produtivas e estrangulamentos de produção são fortes. Nas fases de crescimento acelerado, as descontinuidades da produção setorial podem ser mascaradas por pressões inflacionárias, déficits crescentes da balança comercial ou, ainda, por taxa de juros reais muito superiores à taxa de crescimento econômico.

De toda forma, a existência de pontos de estrangulamentos de produção não se constitui em uma exceção à dinâmica da acumulação capitalista. Em outras palavras, o caráter atomizado das decisões capitalistas em tanto que produção de mercadorias não garante, a priori, as condições para a reprodução econômica. Isto posto, o interesse em representar as trajetórias de crescimento equilibrado, dado que essas quase nunca são verificadas, encontra-se em compará-las com as trajetórias observadas de crescimento, com o intuito de identificar descontinuidades produtivas e pontos de estrangulamentos da produção. Na seção que se segue, apresentam-se os procedimentos metodológicos para hierarquizar os setores produtivos quanto à importância para a garantia das condições de crescimento em longo prazo e determinar uma trajetória de crescimento equilibrado compatível com uma regra de distribuição inscrita em dada estrutura de demanda final. 


\section{Procedimentos metodológicos}

Recordando o objetivo deste trabalho, busca-se estudar a capacidade da economia brasileira de sustentar taxas de crescimento em longo prazo por meio de complementaridades técnicas intersetoriais como vetor de absorção e difusão tecnológicas na estrutura industrial. Essas complementaridades são estimadas em conformidade com um modelo de crescimento multissetorial de inspiração neorricardiana do tipo Sraffa-Von Neumann. Esse modelo gera uma trajetória de crescimento balanceado a taxa máxima de expansão, compatível com uma estrutura de repartição de renda inscrita em um vetor de demanda final. Com essa trajetória de crescimento, todas as complementaridades técnicas entre os setores produtivos são atendidas. Em outras palavras, as proporções da produção setorial geradas por essa trajetória garantem as condições para o crescimento balanceado. Dessa forma, quando se comparam essas proporções com aquelas efetivamente observadas na economia, podem-se identificar excedentes ou estrangulamentos de produção, quando, respectivamente, a produção observada de um setor qualquer for maior ou menor que a produção do crescimento balanceado.

Os estrangulamentos da produção que possam ser identificados serão capazes de comprometer o crescimento econômico em longo prazo se localizados em setores básicos. Quanto mais básicos forem os setores estrangulados, maior o comprometimento das condições para o crescimento em longo prazo. Assim, para qualificar os possíveis pontos de estrangulamentos da produção, torna-se necessário mensurar o grau de basicidade dos setores produtivos inscritos na Matriz A de Coeficientes Técnicos, representativa da estrutura produtiva da economia. Com base nessas premissas, na sequência desta seção, desenvolvem-se dois modelos. O primeiro, correspondente à "trajetória dourada" do modelo Sraffa-Von Neumann, serve para estimar o grau de basicidade dos setores produtivos da Matriz A de Coeficientes Técnicos utilizada para representar a estrutura produtiva da economia brasileira e qualificar os possíveis pontos de estrangulamentos da produção. O segundo modelo, correspondente à "trajetória prateada" do Modelo de Sraffa-Von Neumann, compatível com uma estrutura de repartição inscrita em um vetor de demanda final efetivamente observado para a economia brasileira no ano de referência, serve para identificar possíveis pontos de estrangulamentos de produção, quando se comparam as proporções da produção setorial que geram crescimento balanceado com as proporções setoriais efetivamente observadas na economia. 


\section{a. A hierarquia da estrutura produtiva}

Com base no Modelo de Sraffa (1960), com o intuito de apreender a importância relativa de cada setor produtivo para reprodução econômica, toma-se como ponto de partida a tecnologia de produção representada por uma Matriz de Coeficientes Técnicos. Pode-se então demostrar que os setores básicos são definidos de acordo com o caso limite em que toda a produção setorial do período t-l (representada pelo vetor de produção, $q_{t-1}$ ) serve de meio de produção no período $t$ (representado pelo vetor de meio de produção, $\mathrm{m}_{t}$ ). Essas relações podem ser representadas pelo seguinte Sistema de Equações (1).

$$
\begin{aligned}
& m_{t}=q_{t-1} \\
& m_{t}=A q_{t} \\
& A q_{t}-q_{t-1}=0
\end{aligned}
$$

Esse sistema indica que toda a produção do período $(t-1)$ - representada pelo vetor $q_{t-1}$ - é usada como meio de produção no período $t$ - representada pelo vetor $m_{\mathrm{t}}$. Assim, $m_{\mathrm{t}}=q_{\mathrm{t}-1}$. Como o vetor de meios de produção (m) é igual ao produto da Matriz A de Coeficientes Técnicos e ao vetor de produção $q$, tem-se: $m_{t}=A q_{t}$. Por simples substituição tem-se, sob a forma matricial, um sistema de equações a diferenças finitas, homogêneo de grau um, que admite solução do tipo descrito pela Equação (2).

$$
q_{t}=(1+\rho) q_{t-1}
$$

Essa equação indica que a economia cresce a uma taxa máxima de expansão igual a $\rho$. Com efeito, dada a Matriz de Coeficientes Técnicos, tem-se que: [1/ $(1+\rho)]$ é um autovalor de $A$; e $q$ é um autovetor de $A$, associado a esse autovalor. Como as quantidades produzidas devem ser estritamente positivas e a Matriz de Coeficientes Técnicos é não negativa, pelos teoremas de Perron-Frobenius, sabe-se que a Matriz $A$ possui um autovalor dominante, aqui igual: $[1 /(1+\rho)]$, que está associado a um autovetor $q$ com todos os elementos positivos. No sistema de Sraffa (1960), o autovetor, $q$, associado ao autovalor dominante da Matriz de Coeficientes Técnicos, representa as proporções das quantidades que, se produzidas, geram uma trajetória de crescimento equilibrado à taxa máxima de expansão. Substituindo (1) em (2) tem-se a Equação (3), que representa 
uma "trajetória dourada" de crescimento balanceado, em que a produção setorial desempenha o papel exclusivo de meios de produção.

$$
A q_{t}=\frac{1}{(1+\rho)} q_{t}
$$

Associando o resultado expresso na Equação (3) ao sistema analítico de Sraffa (1960), observa-se que os setores cujos produtos não exercem nenhuma função como meios de produção apresentam um peso igual a zero no vetor característico, $q$. Eles se denominam setores não básicos. Os outros setores serão denominados básicos porque toda a economia dependerá direta ou indiretamente de suas produções. Acrescenta-se uma nuance analítica à taxonomia proposta por Sraffa (1960). No lugar da classificação binária em setores básicos e não básicos, utilizada por Sraffa, supõe-se a existência de diferentes graus de basicidade. Argumenta-se que a proporção da produção setorial na trajetória de crescimento, em que todo produto serve de meios de produção, oferece uma medida dessa hierarquização da estrutura produtiva e, portanto, uma medida do grau de basicidade dos setores produtivos. Como em Sraffa, os setores não básicos continuam a apresentar peso igual a zero na estrutura reprodutiva da economia. Todavia, quanto maior o peso de um setor na estrutura reprodutiva, maior o grau de basicidade.

Em acordo com os procedimentos propostos, o grau de basicidade serve para qualificar a amplitude das descontinuidades da produção industrial capazes de comprometer as condições de crescimento em longo prazo. O grau de basicidade representa uma medida da intensidade com a qual a ausência de complementaridades da produção setorial pode influenciar negativamente a dinâmica de crescimento econômico em geral e, por conseguinte, a transmissão de inovações tecnológicas. Se os estrangulamentos da produção se encontram localizados em setores básicos da economia, há riscos de as descontinuidades da produção setorial comprometerem os canais de difusão e absorção de inovações tecnológicas e as condições de crescimento em longo prazo. 


\section{b. As condições para reprodução econômica}

Pode-se demonstrar que a taxa máxima de crescimento equilibrado derivada do sistema de Sraffa (1960) é também igual a taxa de lucro da economia descrita pela Matriz de Coeficientes Técnicos. Para isso considera-se que a economia seja capaz de produzir um excedente $(f)$ sobre a reposição dos meios de produção $(m)$. Uma parte desse excedente é destinada ao consumo final, cujo perfil pode ser descrito pelo vetor de demanda final, $f_{c}$; e outra parte é destinada aos investimentos líquidos da economia, descritos pelo vetor $f_{r}$. Desse modo, essas relações podem ser escritas em termos matriciais da seguinte forma:

$$
\begin{aligned}
& q=m+f \\
& f=f_{c}+f_{r}
\end{aligned}
$$

A produção de cada setor, descrita pelo vetor q, reparte-se entre demanda intermediária industrial (m) e demanda final (f). A demanda final setorial reparte-se, por sua vez, em consumo $\left(\mathrm{f}_{c}\right)$ e investimentos $\left(\mathrm{f}_{r}\right)$. As condições de concorrência garantem que a taxa de lucro R seja a mesma para todos os setores produtivos. Por fim, para apreender a hierarquia dos setores produtivos em graus de basicidade, supõe-se, como foi feito anteriormente por meio das Equações (1) e (2), que o consumo final da economia seja igual a zero, $f_{c}=0$. Desse modo, a Equação (4) poder ser reescrita como se segue:

$$
\begin{aligned}
& q=m+f_{r} \\
& f_{r}=R m \\
& q=m+R m \\
& q=(1+R) m \\
& q=(1+R) A q \\
& A q=\frac{1}{(1+R)} q
\end{aligned}
$$

Essa relação mostra que a taxa máxima de crescimento $\rho$ da Equação (3) é exatamente igual à taxa máxima de lucro $\mathrm{R}$ da Equação (5), para quando todo o excedente da produção é utilizado como meio de produção. 
Entretanto, essa equação serve apenas para hierarquizar os setores produtivos segundo diferentes graus de basicidade. Resta agora determinar a trajetória de crescimento econômico que respeite as complementaridades da produção setorial e seja compatível com uma estrutura de repartição de renda inscrita em um vetor de demanda final.

Essa trajetória não é nunca uma proporção fixa da produção inscrita pela hierarquia dos setores produtivos. Isso implicaria eliminar a produção de certos bens finais que não exercem a função de meios de produção ou, de outro lado, fazer com que fossem consumidos certos bens que têm uso exclusivo de meios de produção. Duas impossibilidades lógicas. Para isso, deve-se construir uma trajetória de crescimento equilibrado a uma taxa máxima de expansão que, simultaneamente, assegure a recomposição dos meios de produção e garanta a realização de uma estrutura de repartição inscrita em um vetor de demanda final.

Essa trajetória de crescimento econômico pode ser representada como uma extensão do modelo anterior utilizado para a hierarquização dos setores produtivos. Para isso, supõe-se que parte do excedente sobre a reposição dos meios de produção destina-se à demanda final. A taxa máxima de expansão dessa economia implica que o excedente da produção sobre o consumo intermediário industrial, $r$, em um período qualquer, seja completamente reinvestido no período seguinte, $f_{r}=r . m$. A concorrência e a possibilidade da mobilidade de capitais entre os setores produtivos garantem que a taxa $r$ seja a mesma para todos os setores da economia. Nesses termos, a representação das complementaridades da produção setorial em uma trajetória de crescimento balanceado supõe regularidade dos investimentos produtivos a uma taxa $r>0$, idêntica para todos os setores que compõem a estrutura industrial. Assim, conhecidos a Matriz de Coeficientes Técnicos; o vetor da produção total (q); o vetor do consumo intermediário $(m)$; o vetor de demanda final $(f)$, pode-se escrever:

$$
\begin{aligned}
& q=m+f_{c}+f_{r} \\
& q=m+f_{c}+r \cdot m \\
& q=(1+r) m+f_{c} \\
& q=(1+r) A q+f_{c} \\
& q=[I-(1+r) A]^{-1} f_{c}
\end{aligned}
$$


Partindo da Equação (4) e por substituições sucessivas, o vetor $q$ expresso na Equação (6) oferece agora as proporções da produção setorial que garantem uma "trajetória prateada" de crescimento equilibrado, compatível com a reposição dos meios de produção e o vetor de demanda final $f_{c}$. Entretanto, este sistema é subdeterminado, pois apresenta $n$ equações e $n+1$ variáveis. É preciso determinar a produção de cada setor expressa pelo vetor $q$ e a taxa de lucro $r$ que sejam compatíveis com dada estrutura de demanda final. A fim de resolver esse sistema, acrescenta-se, em acordo com o modelo de Sraffa (1960), a taxa de salários (w) como uma parcela do excedente econômico, de modo que $f_{c}=w . f$. Dito isso, tomando por base as Equações (4) e (5), por meras substituições, pode-se estabelecer uma relação entre lucros, salários e crescimento econômico, conforme a Equação (7).

$$
\begin{aligned}
& f=f_{c}+f_{r} \\
& f=R \cdot m \\
& f_{c}=w \cdot f \\
& f_{r}=r \cdot m \\
& r=R(1-w)
\end{aligned}
$$

Essa relação do sistema de Sraffa (1960) revela estreita correlação entre crescimento econômico, tecnologia e distribuição da renda entre lucros e salários. Basta verificar que a taxa máxima de lucro $[\mathrm{R}=(1-1 / \rho)]$ guarda estreita relação com a raiz característica dominante associada à Matriz de Coeficientes Técnicas $(A)$, e que mudanças na composição da demanda final alteram a trajetória de crescimento econômico. Dessas constatações, extraem-se duas relações importantes. Primeira, a taxa de crescimento compatível com o vetor de demanda final situa-se entre 0 e R. Segunda, a taxa de salários situa-se entre 0 e 1 . Para completar, toma-se a taxa de salários por unidade de trabalho homogêneo como uma proporção do produto líquido e normaliza-se o produto líquido para a unidade, $p^{\prime} f=1$, em que $p$ ' é o vetor teórico de preços de produção, conforme a definição da mercadoria padrão de Sraffa. Dessa forma, a taxa de salários monetários pode ser expressa como se segue por meio da Equação (8): 


$$
\begin{aligned}
& f_{c}=w \cdot f \\
& p^{\prime} f_{c}=w \cdot p^{\prime} f \\
& p^{\prime} f=1 \\
& w=p^{\prime} f_{c}
\end{aligned}
$$

Teoricamente, no modelo de Sraffa, a taxa de salários é expressa em unidades de trabalho homogêneo. Em termos práticos, para o desenvolvimento empírico do modelo desenvolvido, não foram realizados esforços para estabelecer a quantidade de trabalho homogêneo em cada setor. Assim, como proxy utilizou-se o coeficiente de trabalho como a quantidade de trabalho empregado pelo setor i $\left(L_{i}\right)$ com relação ao total de trabalho da economia como um todo $(\mathcal{L})$. Com isso, o coeficiente de trabalho por unidade de produção $(l)$ pode ser expresso como uma medida da produtividade do trabalho, em acordo com a Equação (9):

$$
l=L \hat{q}^{-1}
$$

Para encontrar os preços de reprodução da economia, procede-se a algumas manipulações algébricas bastante simples. Primeiro, multiplica-se a Equação (6), que descreve a trajetória de crescimento equilibrado, pelo vetor linha de preços de equilíbrio. Para isso, é necessário, antes de tudo, transformar os vetores de quantidade e demanda final em matrizes diagonais, representadas a seguir por um circunflexo acima dessas variáveis. Desse modo:

$$
p^{\prime} \hat{q}=(1+r) p^{\prime} A \hat{q}+p^{\prime} \hat{f}_{c}
$$

Segundo, como a soma dos coeficientes de trabalho é por definição igual à unidade, essa relação pode ser expressa em termos matriciais pela multiplicação do vetor linha de coeficientes de trabalho pelo vetor coluna unitário $\mathrm{u}$, de modo que $L u=1$. De outro lado, sabe-se que o vetor unitário, quando transformado em uma matriz diagonal, gera uma Matriz Identidade. Com isso, a taxa de salários descrita pela Equação (8) pode ser assim reescrita: 


$$
\begin{aligned}
& w L u=p^{\prime} f_{c} \\
& w L \hat{u}=p^{\prime} \widehat{f}_{c} \\
& w L=p^{\prime} \widehat{f}_{c} \\
& w . l . \hat{q}=p^{\prime} \widehat{f}_{c}
\end{aligned}
$$

Substituindo a Equação (11) na Equação (10), os preços de reprodução, compatíveis com uma trajetória de crescimento equilibrado, são, agora, determinados conforme a Equação (12):

$$
p^{\prime}=w l[I-A(1+r)]^{-1}
$$

Considerando a Equação (6) de quantidades de reprodução e a Equação (12) de preços de reprodução, tem-se um sistema dual de preços e quantidades com $2 n+1$ equações e $2 n+2$ variáveis. Entretanto, depreende-se de Sraffa (1960) que esse sistema apresenta solução numérica única estabelecida pelo seguinte algoritmo, cuja representação esquemática em termos de diagrama de fluxo encontra-se na Figura 1. Como a taxa de salários varia entre 0 e 1, em busca da redução dos números de interações atribui-se um valor inicial a $w$ igual a 0,5 . Com esse valor, calcula-se a taxa de lucro (r) correspondente. De posse das taxas de salários e lucros, calcula-se a estrutura de preços relativos, inscrita no vetor $p^{\prime}$, que garante a coerência reprodutiva do modelo. Esse vetor de preços corresponde à solução primal do modelo. Com os preços relativos, calcula-se a taxa de salários $\left(w^{*}\right)$ compatível com o vetor de demanda final $(f)$. Se a taxa de salários calculada difere da taxa de salários que deu partida ao algoritmo, substitui-se esse valor no início da rotina e reiniciam-se os cálculos até que haja convergência entre $w$ e $w^{*}$. Quando isso acontece, calcula-se então o dual dos preços de reprodução correspondente às quantidades que descrevem a trajetória de crescimento compatível com a estrutura de demanda final $\left(\mathrm{f}_{c}\right)$. 


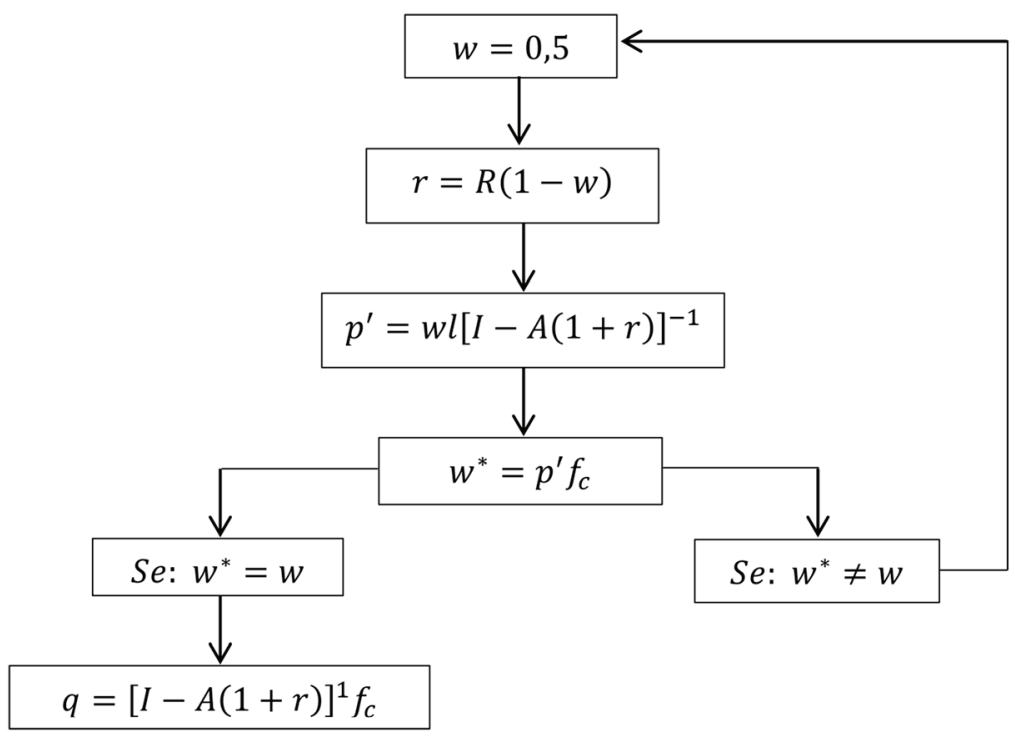

Figura 1 - Algoritmo para definição da Trajetória de Crescimento Equilibrado

Encontrada a representação das condições necessárias à reprodução econômica e à hierarquização da estrutura produtiva, podem-se identificar possíveis pontos de estrangulamento da produção que colocam em xeque a coerência da estrutura industrial da economia brasileira, descrita por meio de uma Matriz de Relações Intersetoriais para o ano de 2013 (MRI-2013). Faz-se esse exercício comparando-se a estrutura produtiva de reprodução com o perfil da estrutura industrial observada. Conforme foi dito, quando a produção observada em um setor qualquer estiver abaixo da produção descrita pela trajetória de crescimento equilibrado é sinal da existência de estrangulamentos de produção. Os estrangulamentos são tão mais severos para as condições de absorção e difusão tecnológicas e de garantia das condições para o crescimento econômico de longo prazo quanto mais básico for o setor concernente. Feito isso, passa-se ao desenvolvimento do exercício de aplicação para o caso da economia brasileira. 


\section{Identificação das descontinuidades técnico-produtivas presentes na estrutura industrial da economia brasileira}

Tendo em vista os modelos propostos nas seções precedentes, esta seção dedica-se à discussão dos problemas das descontinuidades da produção setorial apresentada na trajetória de crescimento da economia brasileira presentes na estrutura industrial descrita por meio da MRI-2013. Essa matriz foi produzida a partir do trabalho de Joaquim José Martins Guilhoto et al. (2016) com base nos dados das Contas Nacionais publicados em 2015. As dimensões das matrizes produzidas por Guilhoto são de 68 setores e 128 produtos. Para os objetivos deste trabalho, tomaram-se 37 setores industriais e 128 produtos. Com essas dimensões e para os setores escolhidos com foco na produção industrial, definiu-se nova Matriz P de Produção e uma nova Matriz Q de Insumos. Calculou-se, então, a Matriz de MarketShare (D) e a Matriz de Insumos por unidade de produção (Q). De forma convencional, seguindo a metodologia do IBGE (2016), pode-se então definir a Matriz A de Coeficientes Técnicos através da Multiplicação da Matriz de Market-Share pela Matriz de Insumos por Unidade de Produção.

Com base na tecnologia da produção descrita pela Matriz A de Coeficientes Técnicos, de acordo com a metodologia proposta, procedeuse à hierarquização dos setores produtivos, revelando a importância de cada um deles para assegurar as condições de crescimento de longo prazo. Em termos técnicos, essa hierarquização é dada pelas proporções do autovetor à direita, associada ao autovalor dominante da Matriz $\mathrm{A}$ de Coeficientes Técnicos. Esse vetor mostra uma escala de dependência técnico-produtiva do conjunto da estrutura industrial da economia brasileira. Quanto maior o peso de cada setor, numa escala de 0 a 100, maior o grau de basicidade. Em outras palavras, quanto maior o peso de cada setor dentro dessa escala, maior a dependência do conjunto da economia para sustentar as taxas de crescimento de longo prazo e acelerar os processos de absorção e difusão de inovações tecnológicas.

Uma vez estabelecida a hierarquia dos setores produtivos e os graus de basicidade, passa-se à identificação de possíveis pontos de estrangulamentos da produção que possam existir na estrutura da economia brasileira. Para isso, tomam-se as proporções da produção setorial observadas na economia brasileira no ano de referência e as compara com a estrutura de reprodução econômica. Quando a produção que garante as condições de reprodução econômica é menor que a produção observada em um dado setor, é sinal da 
existência de estrangulamento da produção nesse mesmo setor. Para avaliar a importância desse estrangulamento no comprometimento das condições de crescimento em longo prazo, verifica-se o grau de basicidade do setor em questão.

A Tabela 1 mostra a hierarquia da estrutura produtiva da economia brasileira, a estrutura da produção que garante o crescimento balanceado e a estrutura da produção efetivamente observada. A Coluna 1 (SETORES) apresenta o nome dos setores que fazem parte da análise. A Coluna 2 (BAS) exibe a hierarquia dos setores produtivos, mostrando, em uma escala de 0 a 100, a importância relativa de cada setor para sustentação de taxas de crescimento de longo prazo. A Coluna 3 (BAC) expõe o grau de basicidade acumulado dos setores produtivos da economia brasileira. A Coluna 4 (OBS) apresenta as proporções da produção setorial da trajetória de crescimento observada. A Coluna 5 (BAL) exibe as proporções da produção setorial da trajetória de crescimento balanceada. Diz-se que um setor se encontra com a produção estrangulada quando a produção observada é menor que a produção balanceada. Os estrangulamentos identificados são mais fortes quanto maior for o grau de basicidade do setor.

Com base nos resultados obtidos, verifica-se a importância crucial dos setores de Extração de Petróleo e Gás, Refino de Petróleo e Energia Elétrica para a manutenção da estrutura produtiva da economia brasileira. Em conjunto, esses três setores respondem por cerca de 56\% da coerência reprodutiva da economia brasileira. As atividades produtivas ligadas a esses setores entram direta e indiretamente na produção de todos os demais setores da economia mais fortemente que qualquer outro setor produtivo. Isso significa que o comprometimento na estrutura produtiva em cada um deles danifica toda a estrutura da economia brasileira, comprometendo as condições de crescimento em longo prazo e as condições para absorção e difusão tecnológicas. 
Tabela 1 - Hierarquia da estrutura produtiva da economia brasileira e estrangulamentos da produção com base na matriz de relações intersetoriais - 2013

\begin{tabular}{|c|c|c|c|c|}
\hline SETORES & BAS & BAC & OBS & BAL \\
\hline Extração de petróleo e gás, inclusive as atividades de apoio & 24,29 & 24,29 & 5,53 & 14,37 \\
\hline Refino de petróleo e coquerias & 18,45 & 42,73 & 3,56 & 9,38 \\
\hline Energia elétrica, gás natural e outras utilidades & 12,99 & 55,72 & 9,15 & 12,46 \\
\hline Fabricação de químicos orgânicos e inorgânicos, resinas e elastômeros & 8,93 & 64,65 & 5,19 & 8,29 \\
\hline Agricultura, inclusive o apoio à agricultura e a pós-colheita & 4,93 & 69,58 & 1,81 & 2,81 \\
\hline Produção de ferro-gusa/ferroligas, siderurgia e tubos de aço sem costura & 3,92 & 73,50 & 1,58 & 2,55 \\
\hline Fabricação de máquinas e equipamentos mecânicos & 2,62 & 76,12 & 0,92 & 1,83 \\
\hline Manutenção, reparação e instalação de máquinas e equipamentos & 2,50 & 78,62 & 2,99 & 3,83 \\
\hline Fabricação de produtos de metal, exceto máquinas e equipamentos & 2,30 & 80,92 & 1,42 & 2,18 \\
\hline Fabricação de defensivos, desinfetantes, tintas e químicos diversos & 2,28 & 83,21 & 0,34 & 0,84 \\
\hline Fabricação de produtos de borracha e de material plástico & 1,77 & 84,97 & 0,56 & 0,95 \\
\hline Metalurgia de metais não ferrosos e a fundição de metais & 1,67 & 86,65 & 2,55 & 2,71 \\
\hline Fabricação de biocombustíveis & 1,56 & 88,21 & 7,60 & 7,69 \\
\hline Extração de minério de ferro, inclusive beneficiamentos e aglomeração & 1,50 & 89,71 & 2,78 & 2,86 \\
\hline Fabricação de máquinas e equipamentos elétricos & 1,48 & 91,19 & 0,83 & 0,80 \\
\hline Fabricação e refino de açúcar & 1,35 & 92,54 & 1,34 & 1,21 \\
\hline Extração de carvão mineral e de minerais não metálicos & 1,07 & 93,61 & 1,51 & 1,34 \\
\hline Fabricação de produtos de minerais não metálicos & 0,98 & 94,58 & 0,44 & 0,14 \\
\hline Outros produtos alimentares & 0,91 & 95,49 & 2,04 & 1,73 \\
\hline Extração de minerais metálicos não ferrosos, inclusive beneficiamentos & 0,78 & 96,28 & 0,74 & 0,42 \\
\hline Fabricação de celulose, papel e produtos de papel & 0,68 & 96,96 & 2,66 & 2,30 \\
\hline Produção florestal; pesca e aquicultura & 0,45 & 97,41 & 2,24 & 1,80 \\
\hline Fabricação de equipamentos de informática, produtos eletrônicos e ópticos & 0,37 & 97,77 & 1,91 & 1,28 \\
\hline Pecuária, inclusive o apoio à pecuária & 0,35 & 98,12 & 1,09 & 0,40 \\
\hline Fabricação de produtos têxteis & 0,34 & 98,46 & 1,23 & 0,53 \\
\hline Fabricação de produtos da madeira & 0,28 & 98,74 & 1,02 & 0,28 \\
\hline Fabricação de outros equipamentos de transporte, exceto veículos auto & 0,25 & 98,99 & 3,31 & 2,39 \\
\hline Fabricação de peças e acessórios para veículos automotores & 0,21 & 99,19 & 1,45 & 0,48 \\
\hline Abate e produtos de carne, inclusive os produtos do laticínio e da pesca & 0,18 & 99,38 & 1,74 & 0,55 \\
\hline Fabricação de produtos de limpeza, cosméticos/perfumaria e higiene & 0,17 & 99,55 & 2,49 & 1,14 \\
\hline Fabricação de produtos farmoquímicos e farmacêuticos & 0,14 & 99,68 & 1,80 & 0,43 \\
\hline Fabricação de móveis e de produtos de indústrias diversas & 0,12 & 99,80 & 3,76 & 2,35 \\
\hline Confecção de artefatos do vestuário e acessórios & 0,06 & 99,86 & 1,92 & 0,46 \\
\hline Fabricação de automóveis, caminhões e ônibus, exceto peças & 0,06 & 99,92 & 2,53 & 0,63 \\
\hline Fabricação de bebidas & 0,04 & 99,96 & 6,43 & 3,44 \\
\hline Fabricação de calçados e de artefatos de couro & 0,04 & 100,00 & 5,98 & 2,14 \\
\hline Fabricação de produtos do fumo & 0,00 & 100,00 & 5,57 & 0,96 \\
\hline
\end{tabular}

$\left({ }^{*}\right)$ As proporções das quantidades de reprodução correspondem ao autovetor à direita associado ao autovalor dominante da Matriz A de Coeficientes Técnicos que, por definição é igual ao maior entre os autovalores. Com base nos dados utilizados, esse autovalor é igual a: 0,36023549269596. 
$\mathrm{Na}$ outra ponta da escala hierárquica, coerente com o que seria esperado em concordância com o modelo teórico, encontra-se a Indústria do Fumo com grau de basicidade igual a zero. Isso significa que a produção de fumo não entra direta ou indiretamente na produção de nenhum outro setor produtivo. Assim, um possível estrangulamento na produção desse setor não geraria nenhum efeito sobre a trajetória de crescimento da economia brasileira. Ainda em coerência com o modelo teórico, outros setores de bens de consumo não duráveis, como Fabricação de Calçados e de Artefatos de Couro, Fabricação de Bebidas, apresentam graus de basicidade muito reduzidos. Ressalta-se o baixo grau de basicidade da Indústria de Fabricação de Automóveis, quarto setor menos básico de toda a economia aqui representada.

A Indústria de Fabricação de Automóveis, em geral, apresenta fortes encadeamentos a montante e a jusante, diretos e indiretos da produção sobre os demais setores da economia, o que a qualifica como um "setor chave". Dessa forma, o baixo grau de basicidade dessa indústria aqui identificado pode parecer contrário ao senso comum, ${ }^{6}$ sobretudo, porque, no Brasil, em particular, a cada recessão mais profunda, governos se apressam em conceder subsídios à indústria automobilística. A justificativa para tal política é que os efeitos dessa indústria sobre a produção agregada se fazem sentir imediatamente, gerando certa recuperação das taxas de crescimento em curto prazo. Entretanto, o que este trabalho demostra é que os incentivos à indústria automobilística não são capazes de sustentar as taxas de crescimento de longo prazo.

Com base nos resultados obtidos, verifica-se que, dos 37 setores em análise, 14 encontram-se com a produção estrangulada. Isso significa que as quantidades efetivamente produzidas por esses setores (produção observada) foram menores do que os requisitos para a reprodução balanceada. Ressaltam-se os estrangulamentos na produção em seis setores cujo grau de basicidade é maior que a média da economia: 1) Extração de petróleo e

6 Os setores chaves são normalmente definidos conforme os índices de encadeamentos de Rasmussen (1956) e Hirschman (1958) e algumas poucas variações, todas decorrentes diretamente da Matriz Inversa de Leontief, cuja referência é Leontief (1951). Em geral, são chaves os setores que apresentam, simultaneamente, Backward Linkage e Forward Linkage maiores que a média da economia. Nessa linha destaca-se o trabalho pioneiro de Eleutério Prado (1981), que aplica esses indicadores para análise da estrutura industrial da economia brasileira. Esses indicadores privilegiam os efeitos de variações da demanda final sobre a produção intermediária industrial. Em outra perspectiva, o conceito de grau de basicidade, aqui adotado, mede o grau de dependência técnica e tecnológica de toda a estrutura produtiva com relação a dado setor. Quanto maior o grau de basicidade de dado setor, maior a dependência da estrutura produtiva com relação a esse mesmo setor para assegurar as condições de crescimento no longo prazo. 
gás, inclusive as atividades de apoio; 2) Refino de petróleo; 3) Energia elétrica, gás natural e outras utilidades; 4) Fabricação de químicos orgânicos e inorgânicos, resinas e elastômeros; 5) Agricultura, inclusive apoio à agricultura e à pós-colheita; e 6) Produção de ferro-gusa/ ferroligas, siderurgia e tubos de aço sem costura. Os estrangulamentos localizados nesses setores, com elevados graus de basicidade, indicam fortes restrições à coerência reprodutiva, às condições que garantem a sustentação do crescimento de longo prazo e ao poder de absorção e difusão de inovações tecnológicas da economia brasileira. ${ }^{7}$ Ante as características da estrutura industrial e os estrangulamentos da produção existentes, a economia brasileira não tem como sustentar taxas de crescimento de longo prazo, pelo menos sem incorrer em pressões inflacionárias e pressões no balanço de pagamentos para complementar a produção doméstica.

\section{Conclusões}

Aplicando o modelo teórico à análise da estrutura produtiva da economia brasileira, constata-se, em primeiro lugar, a existência de pontos de estrangulamento na produção industrial. Em segundo lugar, averigua-se que os pontos de estrangulamento encontram-se prioritariamente localizados em setores básicos da economia. As desproporções entre a produção setorial podem ser vistas e analisadas de duas maneiras. Primeira, há uma insuficiência na produção de setores básicos por falta de investimentos. Segunda, há um excedente na produção de bens de consumo não duráveis e de bens de consumo duráveis, destacadamente na fabricação de automóveis. Neste último caso, talvez a explicação esteja em um excedente de crédito concedido de forma cíclica para elevar as taxas de crescimento no curto prazo, que não se sustentarão em longo prazo, dado o baixo grau de basicidade da produção desse setor.

7 Mauro Oddo, Ricardo Infante e Carlos Mussi (2014) demonstram que, ao longo do tempo, a heterogeneidade estrutural da economia brasileira não foi reduzida. Em um segundo trabalho mais amplo organizado por esses mesmos autores, Ricardo Infante, Mauro Oddo, e Carlos Mussi (2015) mostram, em repetidos capítulos, que a heterogeneidade estrutural da economia brasileira se materializa em desigualdades da produtividade inter e intrassetorial, limitadoras das condições de crescimento em longo prazo. Aqui, supõe-se que heterogeneidade estrutural se manifesta também por ausência de complementaridades da produção setorial. Em acordo com esses autores e em geral com outros estudos da CEPAL aqui citados, reafirma-se que heterogeneidade estrutural compromete as condições de crescimento em longo prazo da economia brasileira e limita as capacidades de absorção e difusão de inovações tecnológicas e de adaptação da economia à dinâmica de acumulação mundial. 
Na presença de pontos de estrangulamentos da produção em setores básicos, os momentos espasmódicos de crescimento da economia brasileira só se explicam por déficits fiscais e do balanço de pagamentos, presentes ou latentes; ou por pressões inflacionárias presentes ou latentes que, cedo ou tarde, acabam por resultar em uma combinação de recessão e inflação para corrigir os estrangulamentos existentes. Dito de outra maneira, as descontinuidades técnico-produtivas presentes na estrutura industrial da economia brasileira condicionam a trajetória de crescimento a recorrentes pressões inflacionárias e a déficits fiscais e de balanço de pagamentos. Em longo prazo, a sustentação do crescimento econômico encontra-se comprometida, a menos que se removam os estrangulamentos da produção por meio de uma política industrial ativa que privilegie os setores de infraestrutura e da indústria de base.

Mesmo considerando que a estrutura industrial da economia brasileira demonstre ser bastante completa em termos do número de setores instalados, essa estrutura necessita de coerência reprodutiva, principalmente em razão da extrema heterogeneidade técnica e tecnológica entre os diversos setores produtivos. Esta heterogeneidade manifesta-se pela ausência de complementaridades da produção setorial, o que compromete as condições de absorção e de difusão das novas tecnologias, perturbando, então, as condições de adaptação da economia brasileira às transformações do paradigma técnico-produtivo.

Do que foi dito até aqui, a continuidade do crescimento da economia brasileira somente é sustentável por fortes pressões inflacionárias derivadas da instabilidade dos preços relativos ou por déficits comerciais necessários para cobrir as insuficiências da demanda interna. Talvez se possa argumentar que pressões inflacionárias ficaram contidas na primeira década dos anos 2000 pela manipulação dos preços administrados, do mesmo modo que os déficits comerciais ficaram mascarados nos últimos anos pelo chamado boom das commodities. Passado esse boom, a sustentação dos preços administrados abaixo dos preços de reprodução tornou-se inviável e os problemas estruturais da economia brasileira voltaram à tona. Em síntese, a menos que se coloque em prática uma política industrial capaz de corrigir os problemas estruturais da economia brasileira, as condições de crescimento em longo prazo permanecerão comprometidas. Mais ainda, as descontinuidades da produção setorial e a presença de estrangulamentos em setores básicos imporão fortes restrições às condições de absorção e difusão das inovações tecnológicas capazes de modernizar e reduzir as heterogeneidades técnico-produtivas presentes na estrutura industrial. 
Um aprofundamento deste estudo demanda a identificação das causas de estrangulamentos tão marcantes na estrutura produtiva da economia brasileira, situados em setores básicos, fundamentais ao funcionamento da economia. Um desdobramento natural deste trabalho consiste em replicar a metodologia adotada para uma série de matrizes de relações intersetoriais, já disponíveis pelo IBGE ou pelo Núcleo de Economia Regional e Urbana da Universidade de São Paulo (NEREUS). Em se fazendo, haveria a possibilidade de discutir mudanças na estrutura produtiva da economia brasileira e os efeitos sobre o crescimento da produtividade e da produção agregadas. Isso se justifica pelo fato de que, ao menos em tese, diferentes setores possuem desiguais intensidades tecnológicas e, portanto, efeitos diversos sobre a produtividade e a taxa de crescimento da economia como um todo.

Do ponto de vista normativo, este trabalho sugere que é preciso definir uma estratégia de competitividade, longe da ideia de construir campeões nacionais e mais próxima de garantir redução das heterogeneidades técnicas e tecnológicas entre os setores produtivos.

Do que foi visto, torna-se necessário fazer com que os objetivos da política industrial sejam compatíveis com uma estratégia de crescimento de longo prazo, com geração de emprego de qualidade e melhoria da repartição de renda. Para isso é preciso remover os estrangulamentos da produção e as descontinuidades dinâmicas intersetoriais que possam ser identificados na estrutura industrial da economia brasileira.

\section{Referências}

Aghion, Philippe e Peter Howitt. 1992. “A Model of Growth through Creative Destruction.” Econometrica 60 (2): $323-351$.

Aghion, Philippe, Ufuk Akcigit, e Peter Howitt. 2013. "What Do We Learn From Schumpeterian Growth Theory?" NBER Working Papers 18824, National Bureau of Economic Research, Inc.

Archibugi, Daniele. 2001. "Pavitt's Taxonomy Sixteen Years on: A Review Article.” Economics of Innovation and New Technology 3: 415-425.

Barro, Robert, Xavier Sala-y-Martin. 1990. "Public Finance in Models of Endogenous Growth.” NBER Working Paper 3419.

Bielschowsky, Ricardo. 2013. "Estratégia de Desenvolvimento e as Três Frentes de Expansão no Brasil: Um Desenho Conceitual.” Texto para discussão - Instituto de Pesquisa Econômica Aplicada 1828. Brasília. 
Cândido, Carolina. 2014. "Avaliação Da Heterogeneidade Estrutural Na Indústria Brasileira: 1996 A 2011." Dissertação de mestrado, Programa de Pós-Graduação em Economia da Universidade Federal de Santa Catarina, Florianópolis.

Campos, Bruno e Ana Ruiz. 2009. "Padrões Setoriais de Inovação na Indústria Brasileira." Revista Brasileira de Inovação 8 (1): 167-210.

Cass, David. 1963. "Optimum Growth In An Aggregative Model Of Capital Accumulation." Review of Economic Studies 32: 233-240.

Catela, Eva, Gabriel Porcile. 2013. "Heterogeneidade Estrutural Na Produtividade Das Firmas Brasileiras." Textos para Discussão CEPAL-IPEA 55.

Castellacci, Fulvio. 2009. "Technological Paradigms, Regimes And Trajectories: Manufacturing And Service Industries In A New Taxonomy Of Sectoral Patterns Of Innovation.” Research Policy 37 (6-7): 978-994.

Castro, Daniela Fernandes de. 2010. "Padrões Setoriais da Inovação Tecnológica na Indústria Brasileira: Uma Análise de Cluster a Partir da Pintec." Dissertação de Mestrado em Economia, Pontifícia Universidade Católica de São Paulo, São Paulo.

CEPAL. 2010. "A Hora Da Igualdade: Brechas Por Fechar, Caminhos Por Abrir.” Trigésimo terceiro período de sessões da CEPAL. Brasília.

Dosi, Giovanni. 1982. “Technological Paradigms And Technological Trajectories: A Suggested Interpretation Of The Determinants And Directions Of Technical Change.” Research Policy 11: 147 - 162.

Freeman, Christopher. 2008. "Systems of Innovation: Selected Essays in Evolutionary Economics." Edward Elgar Publishing Ltd.

Geels, Frank. 2004. "From Sectoral Systems Of Innovation To Socio-Technical Systems". Research Policy 33: $897-920$.

Grossman, Gene e Elhanan Helpman. 1991. "Innovation and Growth in the Global Economy." MIT Press: Cambridge.

Guilhoto, Joaquim e Umberto Sesso Filho. 2010. "Estimação da Matriz Insumo-Produto Utilizando Dados Preliminares das Contas Nacionais: Aplicação e Análise de Indicadores Econômicos para o Brasil em 2005." Economia \& Tecnologia 6 (23).

Guilhoto, Joaquim et al. 2016. "Sistema de Matrizes de Insumo-Produto, Brasil (1995-2013).”NEREUS - Núcleo de Economia Regional e Urbana da USP. Acesso em 26/02/2017. http://www.usp.br/nereus/?dados=sistema-de-matrizes-de-insumo-produto-brasil-1995-2013.

Hamberger, Paula, Marisa Botelho. 2015. "Padrões Setoriais De Inovação Das Pequenas E Médias Empresas Industriais Brasileiras: Uma Análise Em Nível Da Firma.” Anais do $43^{\circ}$ Encontro Nacional de Economia: 1-20.

Hirschman, Albert. 1958. "The Strategy Of Economic Development.” New Haven: Yale University Press.

Infante, Ricardo, Carlos Mussi e Mauro Oddo. 2015. "Por Um Desenvolvimento Inclusivo: O Caso Do Brasil." Comissão Econômica para a América Latina e o Caribe (CEPAL). Santiago do Chile.

Instituto Brasileiro de Geografia e Estatística (IBGE). 2016. "Matriz De Insumo-Produto: Brasil: 2010” IBGE - Coordenação de Contas Nacionais. Rio de Janeiro: IBGE.

Kalecki, Michal. 1977. “O Problema Da Demanda Efetiva Em Tugan-Baranovski e Rosa Luxemburgo.” In Michal Kalecki. Crescimento e Ciclo Das Economias Capitalistas. São Paulo: Hucitec.

Koopmans, Tjalling. 1963. “On The Concept Of Optimal Economic Growth.” In Study Week on the Econometric Approach to Development Planning, chap. 4: 225-87. North-Holland Publishing Co., Amsterdam.

Leontief, Wassily. 1951. “A Economia de Insumo-Produto.” In W. Leontief. A Economia do Insumo-Produto. 1985. São Paulo: Nova Cultural. Publicado em Scientific American (October): 15-21.

Lucas, Robert. 1988. “On the Mechanics of Economic Development.” Journal of Monetary Economics 22: 3-42. 
Lundvall, Bengt-Ake. 1988. "Innovation as an Interactive Process: From User-Producer Interaction to the National Systems of Innovation.” In G. Dosi et al. (eds). Technical Change and Economic Theory. London: Pinter. Lundvall, Bengt-Ake. 1992. "National Systems of Innovation. Towards a Theory of Innovation and Interactive Learning.” Edited by Bengt-Ake Lundvall. Pinter Publishers: London.

Malerba, Franco e Richard Nelson. 2011. "Learning And Catching Up In Different Sectoral Systems: Evidence From Six Industries.” Industrial and Corporate Change 20 (6): 1305 - 1334.

Malerba, Franco. 2002. “The Sectoral System Of Innovation And Production.” Research Policy 31: $247-264$.

Marconi, Nelson, Igor Rocha, Guilherme Magacho. 2016. "Sectoral Capabilities And Productive Structure: An Input-Output Analysis Of The Key Sectors Of The Brazilian Economy.” Revista de Economia Política 36 (3): $470-492$.

Mazzucato, Mariana. 2013. "Financing Innovation: Creative Destruction Vs. Destructive Creation.” Industrial and Corporate Change 22 (4).

Mazzucato, Mariana. 2014. "O Estado Empreendedor: Desmascarando O Mito Do Setor Privado Vs. Setor Público.” Portfolio-Penguin.

Nelson, Richard e Sidney Winter. 1982. “An Evolutionary Theory of Economic Change”. Harvard University Press.

Oddo, Mauro, Ricardo Infante e Carlos Mussi. 2014. "Produtividade Do Trabalho E Heterogeneidade Estrutural No Brasil Contemporâneo". In F. De Negri, L. R. Cavalcante. Produtividade no Brasil: Desempenho E Determinantes. Brasília: ABDI, Ipea.

Pavitt, Keith. 1984. "Sectoral Patterns Of Technical Change: Towards A Taxonomy And A Theory." Research Policy 13 (6): 343-373.

Perez, Carlota. 2009. "Technological Revolutions and Techno-economic Paradigms." In Working Papers in Technology Governance and Economic Dynamics, Working Paper 20. Tallin: Norway and Tallinn University of Technology.

Pereira, Vinícius. 2016. “As Transformações Na Estrutura Produtiva Brasileira Na Era Do Real: Uma Abordagem Insumo-Produto Comparada.” XXI Encontro Nacional de Economia Política. São Bernardo do Campo.

Pinto, Aníbal. 1969. “Natureza E Implicações Da 'Heterogeneidade Estrutural’ Da América Latina.” In R. Bielschowsky (org.). 2000. Cinquenta Anos De Pensamento Da Cepal. Rio de Janeiro: Editora Record.

Prado, Eleutério. 1981. “Estrutura Tecnológica E Desenvolvimento Regional.” São Paulo: IPE/USP.

Rasmussen, Poul Norregaard. 1956. "Studies In Intersectoral Relations.” Amsterdam: North-Holland.

Rebelo, Sergio. 1991. "Long-Run Policy Analysis and Long-Run Growth.” Journal of Political Economy 96: 500-521.

Robinson, Joan. 1956. "The Accumulation of Capital.” London: Macmillan.

Romer, Paul. 1990. "Endogenous Technological Change.” Journal of Political Economy 98: S71-S102.

Romer, Paul. 1986. "Increasing Returns and Long-Run Growth.” Journal of Political Economy 94: 1002-1037.

Silva, Conceição de Fátima, Wilson Suzigan. 2014. "Padrões Setoriais De Inovação Da Indústria De Transformação Brasileira.” Estudos Econômicos 44 (2): 277-321.

Solow, Robert. 1956. "A Contribution to the Theory of Economic Growth". The Quarterly Journal of Economics 70 (1): 65-94.

Solow, Robert. 1957. "Technical Change and the Aggregate Production Function." The Review of Economics and Statistics 39 (3): 312-320.

Sraffa, Piero. 1985. Produção De Mercadorias Por Meio De Mercadorias: Prelúdio A Uma Crítica Da Teoria Econômica. Coleção Os Economistas. São Paulo: Abril Cultural. 